\title{
Combating Triple Burden of Malnutrition in Children
}

\author{
Prema Ramachandran \\ Nutrition Foundation of India, Qutab Institutional Area, New Delhi, India \\ nutritionfoundationofindia@gmail.com
}

I $\mathrm{t}$ is well recognised that dietary intake in school-age children plays a major role in defining nutritional and health status not only during childhood and adolescence but also during adulthood. Surveys carried out by the National Nutrition Monitoring Bureau between 1972 and 1997 showed that low dietary intake, undernutrition and anemia were major public health problems in school-age children [1]. The school mid-day meal program was initiated in 1995 to reduce class room hunger and undernutrition [2]. In the last two decades, research studies - mostly from urban areas - highlighted the emerging problem of overnutrition, especially among affluent urban segments.

Fourth District Level Household Survey (DLHS-4) [3] and Clinical, Anthropometric and Biochemical (CAB) component of Annual Health Survey [4] provided for the first time, country-wide, district- and state-specific data on nutritional status of school-age children. Data from these surveys showed that school-age children across the country faced triple burden of malnutrition; but there were substantial differences between districts and states in prevalence of these problems.

India currently has the largest number of undernourished and anemic children in the world because of the high prevalence of undernutrition (20-30\%) and anemia (70-87\%) [5]. Therefore, the ongoing programs to combat undernutrition and anemia will have to be continued and effectively implemented. Data from these surveys show that if body mass index (BMI)-for-age is used as the parameter for assessment of nutritional status, over $70 \%$ of school age children in India were normally nourished [5]. Every effort should be made to ensure that they continue taking appropriate diet, undertake adequate physical activity, and remain normally nourished.

Prevalence of overnutrition in Indian school children is among the lowest (0.6 to 5.2\%) in the world [5], but because India is a population billionaire, the country is the home to the largest number of overnourished school- age children. Data from research studies indicate that increasingly sedentary lifestyle is the most important factor leading to overnutrition. Increasing physical activity at school and at home is the critical intervention needed to prevent rise in overnutrition.

Almost all studies on overnutrition in school-age children have reported an association between overnutrition and habitual consumption of energy-dense but micronutrient-poor food stuffs. The unhealthy food stuffs come from different sources - from increasing use of oil at home for preparing easy-to-cook fried food, relatively inexpensive tasty street foods (samosas, kachoris, vadas), readily available ultra-refined industrially processed food containing sugar, oil, fat, salt (variously called HFSS food, fast food, junk food), and sugar-sweetened beverages (fruit juices and drinks, carbonated drinks, energy drinks). Vigorous nutrition and health education campaigns highlighting the hazards associated with habitual consumption of unhealthy food stuffs is being undertaken by all agencies. It is expected that the increasingly aware, literate population will take steps first to prevent further increase, and then to reduce consumption of unhealthy food stuffs.

In this context, the development of Guidelines on the Fast and Junk Foods, Sugar-sweetened Beverages, Fruit Juices and Energy Drinks by the Indian Academy of Pediatrics (IAP) [6] is timely. The Nutrition Chapter of the IAP had constituted a National Consultative Group with a mandate to:

- review the evidence and formulate consensus statements related to terminology, magnitude of problem and possible ill effects of junk foods, fast foods, fruit juices, sugar-sweetened beverages and carbonated drinks; and

- formulate recommendations for limiting consumption of these foods and beverages in Indian children and adolescents.

The Group after review of all available data and discussions: 
- recommended use of a new acronym for unhealthy food - JUNCS food (Junk foods, Ultra-processed foods, Nutritionally-inappropriate foods, Caffeinated/colored/carbonated foods/beverages, and Sugar-sweetened beverages);

- concluded that consumption of these JUNCS foods and beverages is associated with higher energy intake leading to higher body mass index and possibly adverse cardio-metabolic consequences in children and adolescents;

- recommended avoiding consumption of the JUNCS by all children and adolescents as far as possible and limit their consumption to not more than one serving perweek;

- advised that no fruit juices/drinks should be given to infants and young children (age $<2$ yrs); intake should be restricted to $125 \mathrm{~mL} /$ day and $250 \mathrm{~mL} /$ day, in children aged $2-5$ yrs and $>5-18$ yrs, respectively;

- supported the ban on sale of JUNCS foods in school canteens and in near vicinity, and suggested efforts to ensure availability and affordability of healthy snacks and foods.

- supported traffic light coding of food available in school canteens;

- recommended legal ban of screen/print/digital advertisements of all the JUNCS foods; and

- suggested communication, marketing and policy/ taxation strategies to promote consumption of healthy foods, and limit availability and consumption of the JUNCS foods.

India has some major advantages while initiating interventions first to contain and then to reverse the overnutrition epidemic in children. Current per capita consumption of processed food and sugar-sweetened beverages in India are lowest in Asia [7]; efforts are being made to ensure that the country retains this enviable position in the coming decades. There is a growing recognition across all segments of population in the country that healthy diets and lifestyles $\mathrm{w}$ ith adequate physical activity are essential for optimal nutrition and health. India identified overnutrition early in the course of the epidemic and initiated programs to prevent further rise in overnutrition. Given these advantages, the country can be expected to achieve the Sustainable development goal for prevention and reduction of overnutrition and associated non-communicable diseases.

Funding: None; Competing interest: None stated.

\section{REFERENCES}

1. National Nutrition Monitoring Bureau (NNMB). Twentyfive Years of NNMB (1972-1997). Available from: $h t t p: / /$ nnmbindia.org/NNMB-PDF\%20FILES/Reports-for\%20 the\%2025\%20years(1972-97).pdf. Accessed August 30, 2019.

2. Ramachandran P. School mid-day meal programme in India: Past, present, and future. Indian J Pediatr. 2019;12:1-6.

3. International Institute of Population Sciences. District Level Household and Facility Survey (DLHS-4) 2014. Available from:https://data.gov.in/.../district-levelhousehold-and-facility-survey-dlhs-4. Accessed August 28, 2019.

4. Office of the Registrar General and Census Commissioner of India. Clinical, Anthropometric and Biochemical (CAB) 2014. Annual Health Survey CAB Component: CAB State Fact Sheets. Available from: $h t t p: / / w w w . c e n s u s i n d i a . g o v . i n /$ 2011 census/hh-series/cab.html. Accessed August 28, 2019.

5. Ramachandran $P$, Kalaivani K. Nutrition transition in India: Challenges in achieving global targets. Proceedings of the Indian National Science Academy. 2018;84:821-33.

6. Gupta P, Shah D, Kumar P, Bedi N, Mittal HG, Mishra K, et al; for Pediatric And Adolescent Nutrition Society (Nutrition Chapter) of Indian Academy of Pediatrics. Indian Academy of Pediatrics Guidelines on the Fast and Junk Foods, Sugar Sweetened Beverages, Fruit Juices, and Energy Drinks. Indian Pediatr. 2019;56:849-63.

7. Baker P, Friel S. Food systems transformations, ultraprocessed food markets and the nutrition transition in Asia. Glob Health. 2016;12:80. 